\title{
PLANTAS DE COBERTURA E ADUBAÇÃO COM NPK PARA MILHO EM PLANTIO DIRETO
}

\section{COVER CROPS AND NPK FERTILIZATION ON CORN UNDER NO-TILLAGE MANAGEMENT}

\author{
Adilson PELÁ ${ }^{1}$ \\ Jaiciclênia da Silva SANTANA ${ }^{2}$ \\ Emmerson Rodrigues de MORAES ${ }^{3}$ \\ Gláucia de Mello PELÁ ${ }^{4}$
}

\begin{abstract}
RESUMO
O presente trabalho teve como objetivo avaliar plantas de cobertura em pré-safra e doses de adubo NPK sobre a produtividade do milho híbrido simples P30K75, cultivado em plantio direto, em alta densidade populacional, na região do Cerrado, em Ipameri-GO. Realizou-se um experimento de campo, em um Latossolo Vermelho-Amarelo Distrófico. $O$ delineamento estatístico foi blocos casualizados, em esquema experimental de parcelas subdivididas, com três repetições. Os tratamentos principais foram constituídos por três espécies utilizadas como plantas de cobertura (Crotalária juncea, Crotalária spectabilis e Brachiária decumbens) e os secundários, por cinco doses (D) de adubos NPK (D1 = 60+50+30; D2 = $120+100+60 ; \mathrm{D} 3=144+120+72 ; \mathrm{D} 4=180+150+90 ;$ e $\mathrm{D} 5=300+250+150 \mathrm{~kg} \mathrm{ha}^{-1}$ de $\left.\mathrm{N}+\mathrm{P}_{2} \mathrm{O}_{5}+\mathrm{K}_{2} \mathrm{O}\right)$. A matéria seca das plantas de cobertura (80 dias após a semeadura) foi de 6271,5197 e $6383 \mathrm{~kg} \mathrm{ha}^{-1}$, para C. juncea, C. spectabilis e $B$. decumbens, respectivamente. Os efeitos de doses de adubos NPK e de espécies de plantas de cobertura sobre o desenvolvimento e produtividade do milho foram independentes. As coberturas $C$. juncea e $C$. spectabilis proporcionaram melhor desenvolvimento e produtividade da cultura do milho que a braquiária. $\mathrm{O}$ incremento das doses de adubo NPK promoveu melhor desenvolvimento e aumento na produtividade de grãos do milho.
\end{abstract}

Palavras-chave: Crotalaria juncea; Crotalaria spectabilis; Brachiaria decumbens.

\begin{abstract}
This study aimed to evaluate the use of cover crops grown in the preharvest period and different doses of the fertilizer NPK on the yield of corn hybrid P30K75 grown in direct plantation, in high population densities, in the Cerrado of Ipameri-GO. It was conducted a field experiment in a dystrophic red-yellow latosol. The statistical design was a randomized block in split-plot experimental scheme with three replications. The main treatments consisted of three species used as cover crops (Crotalaria juncea, Crotalaria spectabilis and Brachiaria decumbens) and the secondary treatments were five different doses of the NPK fertilizer (D1 = $60+50+30, D 2=120+100+60$; D3 = $144+120+72,180+150+90=\mathrm{D} 4, \mathrm{D} 5=300+250$ $+150 \mathrm{~kg} \mathrm{ha}^{-1} \mathrm{~N}+\mathrm{P}_{2} \mathrm{O}_{5}+\mathrm{K}_{2} \mathrm{O}$ ). The dry matter of the cover crop (80 days after sowing) was 6271,5197 and $6383 \mathrm{~kg} \mathrm{ha}^{-1}$ for $C$. juncea, C. spectabilis and B. decumbens, respectively. The effects of NPK doses and coverage plant species on the development and corn yield were independent. The cover crops $C$. juncea and $C$. spectabilis provided better development and productivity of maize than Brachiaria. The increasing in NPK levels promoted better development and increased the productivity of maize.
\end{abstract}

Key-words: Crotalaria juncea; Crotalaria spectabilis; Brachiaria decumbens.

\footnotetext{
${ }^{1}$ Engenheira Agrônoma, Dra. Pesquisadora da Embrapa Clima Temperado, Melhorista Bolsista do CNPq, Caixa Postal 403, Pelotas, RS, Brasil, CEP 96001-970. E-mail: bassols@cpact.embrapa.br. Autora para correspondência.

${ }^{2}$ Presidente da Fundação de Amparo à Pesquisa Edmundo Gastal, Pesquisador aposentado da Embrapa Clima Temperado. E-mail: bonifacionakasu@gmail.com

${ }^{3}$ Pesquisador da Embrapa Clima Temperado, Fitotecnista. E-mail: jfmp@cpact.embrapa.br
} 
PELÁ, A. et al. Plantas de cobertura e adubação...

\section{INTRODUÇÃO}

A produtividade média da cultura do milho nas últimas safras no Brasil ficou em torno de 3.000 $\mathrm{kg} \mathrm{ha}^{-1} \mathrm{e}$, em Goiás, $5.000 \mathrm{~kg} \mathrm{ha}^{-1}$ (CONAB, 2009). Essas produtividades são baixas quando comparadas ao potencial genético da espécie, que pode ultrapassar $12.000 \mathrm{~kg} \mathrm{ha}{ }^{-1}$, ou às produtividades obtidas com o uso de tecnologia mais avançada. Entre as causas principais da baixa produtividade dessa cultura nas áreas de cerrado, encontram-se a baixa fertilidade natural dos solos, a presença de teores elevados de alumínio tóxico e o emprego de técnicas de manejo que favorecem a degradação do solo (Coelho \& França, 1995; Moura et al., 2006).

O plantio direto é um sistema conservacionista, capaz de manter ou melhorar a fertilidade do solo, e proporcionar maior produtividade às culturas. Para a implantação do sistema de plantio direto, a manutenção da cobertura do solo, dentro de um programa de rotação de culturas é um dos fatores imprescindíveis (Carvalho et al., 2007). As plantas de cobertura de solo constituem importante componente em sistemas agrícolas, protegendo o solo da erosão, facilitando a ciclagem de nutrientes, adicionando $\mathrm{N}$ ao solo via leguminosas e mantendo a umidade do mesmo após seu manejo (Derpsch et al., 1985). A decomposição do material vegetal libera gradativamente os nutrientes reciclados, disponibilizando-os à cultura em sucessão, razão pela qual também pode gerar economia no uso de fertilizantes (Derpsch et al., 1985). Indiretamente, pode ser obtido um ganho ambiental, em função da menor utilização de insumos por $\mathrm{kg}$ de produto colhido. Se a baixa disponibilidade de nutrientes pode limitar a produção, aplicações excessivas de adubos, além de constituir um desperdício financeiro, muitas vezes podem poluir o ambiente, como no caso da adubação nitrogenada em excesso. Muitos nutrientes utilizados nas adubações, como fósforo e potássio, são provenientes de reservas minerais não renováveis. O aumento na produtividade é importante para evitar o desmatamento para a incorporação de novas áreas e atender à demanda crescente por alimentos.
A redução no espaçamento entrelinhas (ou aumento na densidade de plantas) vem sendo muito utilizada nos cultivos de milho, com resultados variados. De acordo com Strieder et al. (2008), aumentos de produtividade com redução do espaçamento entre linhas ocorrem quando são adotados altos níveis de tecnologia. Flex \& Vieira (2004) não verificaram diferenças na produtividade de grãos de milho em função da população. Argenta et al. (2001) obtiveram aumentos de produtividade com densidade de 50 mil plantas por hectare, com híbridos de porte baixo. Já Pelá et al. (2008), avaliando doses de adubo formulado NPK (167 a $835 \mathrm{~kg} \mathrm{ha}^{-1}$ ) e populações de plantas, verificaram aumentos lineares com as doses de fertilizante. São necessárias, portanto, mais pesquisas, para ajustar as recomendações de adubações para a cultura do milho em sistema que envolva o uso de populações mais elevadas e diferentes plantas de cobertura.

Este trabalho teve como objetivo avaliar plantas de cobertura do solo em pré-safra e doses de adubo NPK sobre a produtividade do milho cultivado em plantio direto e alta densidade populacional na região de Ipameri-GO.

\section{MATERIAL E MÉTODOS}

O experimento foi desenvolvido em área da Universidade Estadual de Goiás, Unidade Universitária de Ipameri, no município de Ipameri$\mathrm{GO}$. As coordenadas geográficas da área são $17^{\circ}$ $42^{\prime} 35^{\prime \prime} \mathrm{S}$ e $48^{\circ} 07^{\prime} 40^{\prime \prime} \mathrm{W}$, com altitude média de $808 \mathrm{~m}$. O clima da região, segundo a classificação de Köppen, é do tipo Cwa Mesotérmico Úmido, caracterizando clima subtropical, com precipitação média anual de $1.750 \mathrm{~mm}$ e temperatura média anual de $25{ }^{\circ} \mathrm{C}$. O solo, segundo EMBRAPA (1999), é classificado como Latossolo VermelhoAmarelo Distrófico.

O delineamento estatístico foi blocos casualizados, em esquema experimental de parcelas subdivididas, com três repetições. Os tratamentos principais foram constituídos por três espécies utilizadas como plantas de cobertura (Crotalária juncea, Crotalária spectabilis e Braquiária decumbens) e, os secundários, por cinco doses de fertilizante formulado NPK (Tabela 1).

TABELA 1 - Composição das doses de adubo NPK nos tratamentos secundários.

\begin{tabular}{ccccc}
\hline Doses & $\mathrm{N}$ & $\mathrm{P}_{2} \mathrm{O}_{5}$ & $\mathrm{~K}_{2} \mathrm{O}$ & Total \\
\cline { 3 - 5 } & 60 & & $\mathrm{~kg} \mathrm{ha}^{-1}$ & \\
\cline { 3 - 5 } D1 & 120 & 50 & 30 & 140 \\
D2 * & 144 & 100 & 60 & 280 \\
D3 & 180 & 120 & 72 & 336 \\
D4 & 300 & 150 & 90 & 420 \\
D5 & 250 & 150 & 700 \\
\hline
\end{tabular}

${ }^{*} \mathrm{D} 2$ corresponde à dose calculada com base nos resultados da análise do solo e na expectativa de produtividade de 6 a $8 \mathrm{t}$ grãos ha-1 (Alves et al., 1999). 
Antes da instalação do experimento coletou -se na área uma amostra de solo composta por 20 sub-amostras na camada de 0-0,20 m de profundidade, para caracterização química do mesmo, conforme metodologia descrita em EMBRAPA (1997). Os resultados foram: $\mathrm{pH}=6,2 ; \mathrm{P}$ $=1,9 \mathrm{mg} \mathrm{dm}^{-3} ; \mathrm{K}=42 \mathrm{mg} \mathrm{dm}^{-3} ; \mathrm{Al}=0 \mathrm{cmol}_{\mathrm{C}} \mathrm{dm}^{-3} ; \mathrm{Ca}$ $=1,6 \mathrm{cmol}_{\mathrm{C}} \mathrm{dm}^{3} ; \mathrm{Mg}=0,8 \mathrm{cmol}_{\mathrm{C}} \mathrm{dm}^{-3} ; \mathrm{H}+\mathrm{Al}=3,3$ $\mathrm{cmol}_{\mathrm{C}} \mathrm{dm}^{-3} ; \mathrm{CTC}=5,8 \mathrm{cmol}_{\mathrm{C}} \mathrm{dm}^{-3} ; \mathrm{V}=43,2 \%$; e M.O. $=26,3 \mathrm{~g} \mathrm{~kg}^{-1}$.

As plantas de cobertura foram semeadas no início de novembro de 2007, em parcelas com 48 $\mathrm{m}^{2}$. As sementes de braquiária foram distribuídas a lanço e incorporadas superficialmente, na base de 40 sementes viáveis por metro quadrado; as crotalárias foram semeadas em sulcos, obtendo-se 25 plantas por metro linear, no espaçamento de 0,50 $\mathrm{m}$ entre linhas. Após 80 dias da semeadura, foram determinadas a produção de massa fresca e seca das plantas de cobertura, em amostras de 0,50 $\mathrm{m}^{2}$ por parcela. Posteriormente, realizou-se a dessecação das plantas com o herbicida glyphosate, na dose de $1,92 \mathrm{~kg}$ do ingrediente ativo por hectare, utilizando-se pulverizador costal manual, aplicandose um volume de calda de $200 \mathrm{dm}^{3} \mathrm{ha}^{-1}$. Nas parcelas com as crotalárias, realizou-se também roçagem após a semeadura do milho.

Com base em análise do solo e na expectativa de produtividade de 6 a $8 \mathrm{t}$ de grãos ha ${ }^{-1}$ (Alves et al., 1999), foi calculada a adubação recomendada, correspondente a $120 \mathrm{~kg}$ de N $(20 \mathrm{~kg}$ na semeadura e o restante em cobertura, com o milho apresentando 6 folhas), $100 \mathrm{~kg}$ de $\mathrm{P}_{2} \mathrm{O}_{5}$ e 60 $\mathrm{kg}$ de $\mathrm{K}_{2} \mathrm{O}$; esta foi a dose de referência (D2) e, as demais, submúltiplos e múltiplos desta (Tabela 1 ). $\mathrm{Na}$ adubação de semeadura utilizou-se o formulado $\mathrm{N}-\mathrm{P}_{2} \mathrm{O}_{5}-\mathrm{K}_{2} \mathrm{O}$ 05-25-15, aplicado a uma profundidade de $0,1 \mathrm{~m}$ na linha de semeadura. $\mathrm{Na}$ adubação de cobertura utilizou-se como fonte de $\mathrm{N}$ a uréia, aplicada na superfície, ao lado das linhas de plantas de milho. O milho, cultivar P $30 \mathrm{~K} 75$, foi semeado manualmente, no dia 19 de fevereiro de 2008, em sistema de plantio direto, colocando-se duas sementes a cada $25 \mathrm{~cm}$ na linha.

As subparcelas foram constituídas de seis linhas de $3 \mathrm{~m}$, com $0,5 \mathrm{~m}$ de espaçamento entre linhas. Foi considerada como área útil da subparcela as quatro linhas centrais, descartando-se $0,5 \mathrm{~m}$ em cada extremidade. Dez dias após a emergência do milho foi realizado o desbaste, deixando-se apenas uma planta a cada $25 \mathrm{~cm}$, estabelecendo-se, portanto, um estande de 80 mil plantas por hectare.

A colheita foi realizada manualmente quando o milho atingiu a maturidade fisiológica, verificada pelo escurecimento da placenta dos grãos da porção mediana da espiga, e o teor de água foi corrigido para $14 \%$. Foram avaliadas, em dez plantas coletadas aleatoriamente na área útil da subparcela, a altura das plantas e da inserção da espiga, o diâmetro do colmo, a quantidade de fileiras e de grãos por espigas e a massa seca de mil grãos. A produtividade de grãos foi obtida a partir da colheita de todas as plantas da subparcela. Os dados foram submetidos à análise de variância,
PELÁ, A. et al. Plantas de cobertura e adubação..

sendo os efeitos das coberturas avaliados pelo teste de Tukey a $5 \%$ de probabilidade, e os efeitos das doses de NPK avaliados por regressão.

\section{RESULTADOS E DISCUSSÃO}

A produtividade de massa seca das plantas de cobertura foi de 6271,5197 e $6383 \mathrm{~kg} \mathrm{ha}^{-1}$, para C. juncea, C. spectabilis e $B$. decumbens, respectivamente, não havendo diferenças significativas entre as espécies. Essas produtividades podem ser consideradas normais em relação às obtidas na região do Cerrado. Sodré Filho et al. (2004) obtiveram produtividade bem inferior de $C$. juncea em sucessão ao milho $(2412 \mathrm{~kg}$ $\mathrm{ha}^{-1}$ de matéria seca por ocasião do florescimento). Torres et al. (2008) obtiveram produtividade inferior para C. Juncea $\left(3900 \mathrm{~kg} \mathrm{ha}^{-1}\right)$ e semelhante com braquiária $\left(6000 \mathrm{~kg} \mathrm{ha}^{-1}\right)$ em pré-safra, quando as produtividades foram, respectivamente, 3700 e 2100 $\mathrm{kg} \mathrm{ha}^{-1}$, quando essas espécies foram cultivadas em sucessão ao milho. De acordo com Alvarenga et al. (2001), para uma boa cobertura do solo, são necessários aproximadamente $6000 \mathrm{~kg} \mathrm{ha}^{-1}$ de matéria seca. Assim, as três espécies, apesar do curto período de cultivo, foram eficientes, em termos de quantidade de massa seca produzida, e podem ser consideradas adequadas para utilização em présafra na região.

Não houve interação significativa entre doses de NPK e plantas de cobertura, para qualquer parâmetro da cultura do milho (Tabela 2), indicando que o efeito destes fatores foram independentes. $\mathrm{Na}$ literatura são escassos os trabalhos que associam o uso de plantas de cobertura e a adubação com NPK na cultura do milho. Interações não significativas entre uso de adubos verdes e calagem e adubação foram obtidos por Faria, Costa \& Faria (2007), na produtividade do meloeiro. Carvalho et al. (2007), estudando a adubação nitrogenada em cobertura no milho, também não encontraram interação significativa entre doses de $\mathrm{N}$ e plantas de cobertura. Já Collier et al. (2006) verificaram necessidades bem inferiores de $\mathrm{N}$ em cobertura para milho em sucessão à $C$. juncea em comparação com feijão de porco.

O diâmetro de colmo aumentou linearmente entre as doses de 140 e $700 \mathrm{~kg} \mathrm{ha}^{-1}$ de NPK (Figura 1a). Esse resultado diverge do obtido por Lucena et al. (2000), que não verificaram diferenças significativas no diâmetro de colmo em função de doses de $\mathrm{N}$ e $\mathrm{P}_{2} \mathrm{O}_{5}$. Houve também diferenças significativas no diâmetro em função do tipo de cobertura, com maiores valores para as leguminosas $(17,7$ e $17,9 \mathrm{~cm}$ para C. juncea e C. Spectabilis, respectivamente) em relação à braquiária, que apresentou diâmetro médio de $14,8 \mathrm{~cm}$ (Tabela 2). Isso provavelmente ocorreu em função da maior disponibilização de $\mathrm{N}$ pelas primeiras, e porque a cultura do milho extrai grandes quantidades deste elemento. Correa et al. (2008) verificaram que crotalária foi mais eficiente que braquiária e milheto no acúmulo de $\mathrm{N}$ pelo milho. 
PELÁ, A. et al. Plantas de cobertura e adubação...

TABELA 2 - Diâmetro do colmo, altura da planta e altura da inserção da primeira espiga (em cm) em função de plantas de cobertura, e análise de variância do experimento

\begin{tabular}{|c|c|c|c|}
\hline Tratamentos & $\begin{array}{l}\text { Diâmetro do colmo } \\
(\mathrm{cm})\end{array}$ & $\begin{array}{c}\text { Altura da planta } \\
(\mathrm{cm})\end{array}$ & $\begin{array}{c}\text { Altura da espiga } \\
(\mathrm{cm})\end{array}$ \\
\hline \multicolumn{4}{|l|}{ Plantas de cobertura } \\
\hline Crotalária juncea & $17,7 \mathrm{a}$ & 167,7 a & $87,4 \mathrm{a}$ \\
\hline Crotalária spectabilis & $17,9 a$ & $165,7 \mathrm{a}$ & $86,9 a$ \\
\hline Braquiária decumbens & $14,8 \mathrm{~b}$ & $147,8 \mathrm{~b}$ & $72,5 \mathrm{~b}$ \\
\hline Teste F plantas de cobertura (parcela) & $14,14^{*}$ & $43,12^{* *}$ & $26,12^{* *}$ \\
\hline $\begin{array}{l}\text { Teste } \mathrm{F} \text { doses de } \mathrm{N}+\mathrm{P}_{2} \mathrm{O}_{5}+\mathrm{K}_{2} \mathrm{O} \\
\text { (subparcela) }\end{array}$ & $7,67^{* *}$ & $5,73^{* *}$ & $14,00^{* *}$ \\
\hline Teste $\mathrm{F}$ interação parcela $\mathrm{x}$ subparcela & $1,49^{\mathrm{NS}}$ & $0,71^{\mathrm{NS}}$ & $0,32^{\mathrm{NS}}$ \\
\hline C.V. (\%) parcela & 10,53 & 4,02 & 7,78 \\
\hline C.V. (\%) subparcela & 5,12 & 3,85 & 4,75 \\
\hline
\end{tabular}

a)

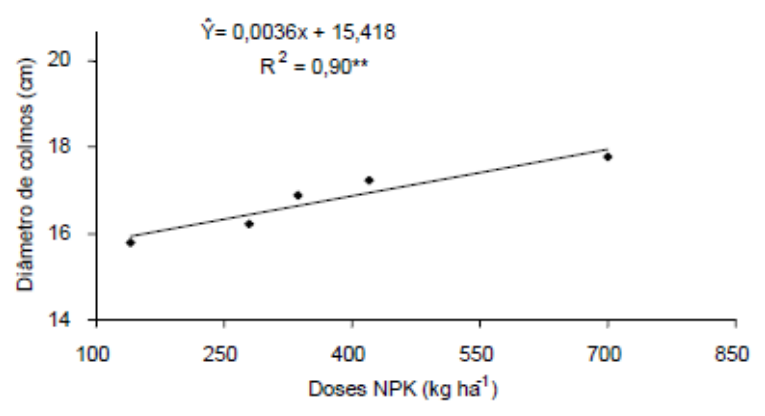

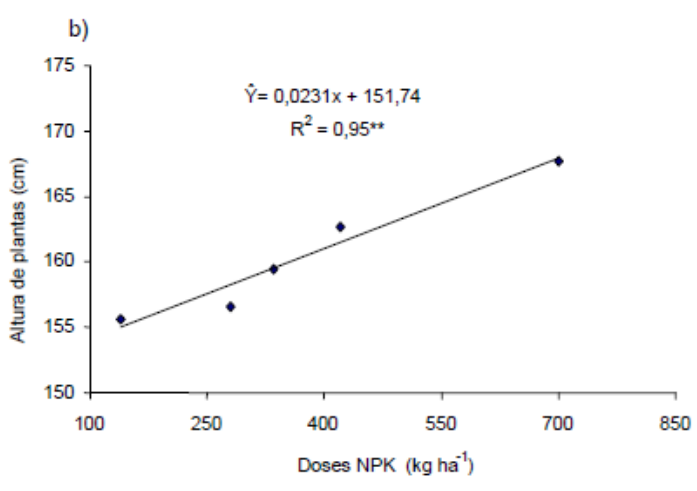

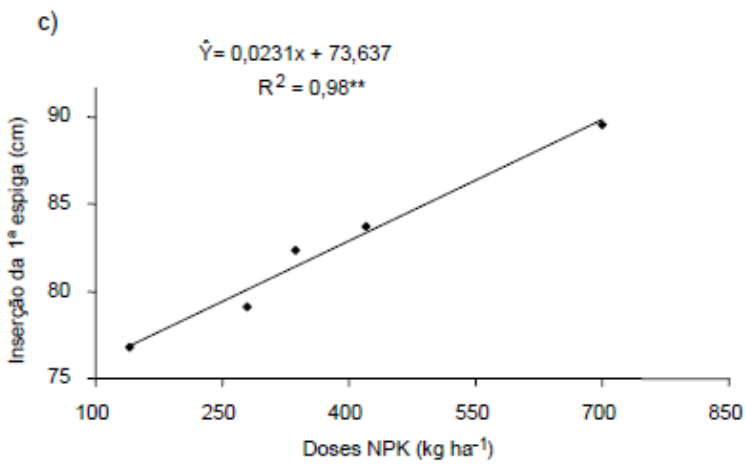

FIGURA 1 - Efeito de doses de adubos NPK sobre a) diâmetro de colmo; b) altura de plantas; e c) altura da inserção da primeira espiga de plantas de milho. ${ }^{* *}=$ Significativo a $1 \%$ de probabilidade pelo teste $\mathrm{F}$.

A altura de plantas aumentou linearmente com as doses de adubo NPK (Figura 1b). Aumentos na altura de plantas também foram encontrados por outros autores. Lucena et al. (2000) verificaram que doses de $100 \mathrm{~kg} \mathrm{ha}^{-1}$ de $\mathrm{N} \mathrm{e}$ $177,3 \mathrm{~kg} \mathrm{ha}^{-1}$ de $\mathrm{P}_{2} \mathrm{O}_{5}$, respectivamente, foram as que proporcionaram maiores alturas, enquanto
Andreotti et al. (2001) constataram aumentos na altura das plantas com a elevação das doses de potássio. A cobertura do solo também interferiu na altura da planta, com maiores valores para $C$. Juncea $(167,7 \mathrm{~cm})$ e C. spectabilis $(165,5 \mathrm{~cm})$ em relação à braquiária, cuja altura foi de $147,8 \mathrm{~cm}$ (Tabela 2). Segundo Silva et al. (2006), a altura da 
PELÁ, A. et al. Plantas de cobertura e adubação...

planta, considerando-se um mesmo cultivar, determina o grau de desenvolvimento da cultura e, geralmente, plantas maiores são mais produtivas, por terem sofrido menos estresse.

A altura da inserção da primeira espiga foi de $78,6 \mathrm{~cm}$ com a dose de $140 \mathrm{~kg} \mathrm{ha}^{-1}$ de NPK, com aumento linear até à dose de $700 \mathrm{~kg} \mathrm{ha}^{-1}$, cuja altura da inserção da primeira espiga foi de $89,6 \mathrm{~cm}$ (Figura 1c). A cobertura do solo também interferiu

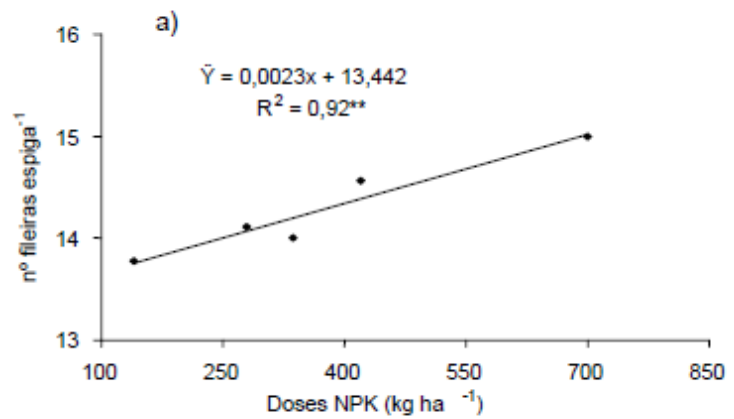

na inserção da primeira espiga, com maiores valores para $C$. juncea e $C$. spectabilis $(87,4$ e 86,9 $\mathrm{cm}$, respectivamente), e em relação à braquiária, com 72,5 cm (Tabela 2).

Houve aumento linear no número médio de fileiras por espiga com o incremento da adubação (Figura 2a). As crotalárias também proporcionaram maior número de fileiras por espiga $(14,7)$ que a braquiária $(13,5)$ (Tabela 3$)$.

b)

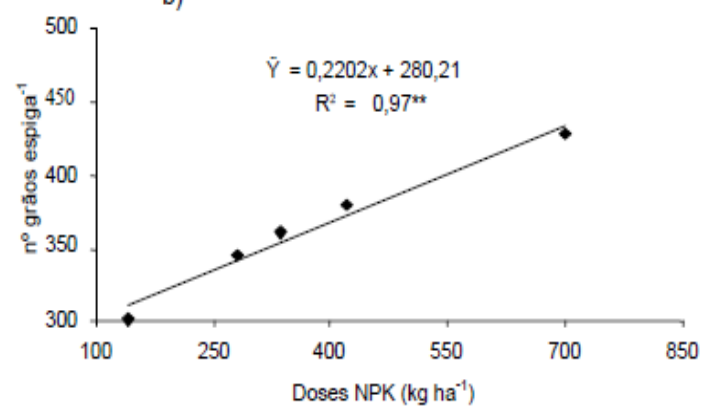

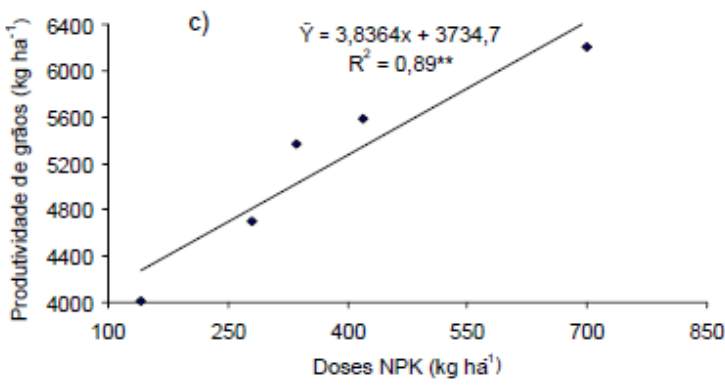

FIGURA 2 - Efeito de doses de adubos NPK sobre a) número de fileiras por espiga; b) número de grãos por espiga; c) massa seca de mil grãos; e d) produtividade de plantas de milho. ${ }^{*} e^{* *}=$ Significativo a 5 e $1 \%$ de probabilidade pelo teste $\mathrm{F}$, respectivamente.

TABELA 3 - Número de grãos por espiga, massa seca de mil grãos (em g) e produtividade (em $\mathrm{kg} \mathrm{ha}^{-1}$ ) em função de plantas de cobertura, e análise de variância do experimento.

\begin{tabular}{|c|c|c|c|c|}
\hline Tratamentos & $\begin{array}{l}\mathrm{N}^{\circ} \text { de fileiras } \\
\text { por espiga }\end{array}$ & $\begin{array}{l}N^{\circ} \text { grãos por } \\
\text { espiga }\end{array}$ & $\begin{array}{c}\text { Massa de mil } \\
\text { grãos secos } \\
(\mathrm{g})\end{array}$ & $\begin{array}{l}\text { Produtividade } \\
\left(\mathrm{kg} \mathrm{ha}^{-1}\right)\end{array}$ \\
\hline \multicolumn{5}{|l|}{ Plantas de cobertura } \\
\hline Crotalária juncea & $14,7 \mathrm{a}$ & 392,4 & 213,7 & 5933,3 a \\
\hline Crotalária spectabilis & $14,7 \mathrm{a}$ & 380,5 & 204,9 & $5600,3 \mathrm{a}$ \\
\hline Braquiária decumbens & $13,5 \mathrm{~b}$ & 315,6 & 203,3 & $3988,7 \quad b$ \\
\hline Teste F plantas de cobertura (parcela) & $9,27^{*}$ & $4,12^{\mathrm{NS}}$ & $0,65^{\mathrm{NS}}$ & $21,42^{* *}$ \\
\hline $\begin{array}{l}\text { Teste } \mathrm{F} \text { doses de } \mathrm{N}+\mathrm{P}_{2} \mathrm{O}_{5}+\mathrm{K}_{2} \mathrm{O} \\
\text { (subparcela) }\end{array}$ & $3,22^{*}$ & $19,42^{* *}$ & $1,90^{\mathrm{NS}}$ & $10,68^{* *}$ \\
\hline $\begin{array}{l}\text { Teste F interação parcela x } \\
\text { subparcela }\end{array}$ & $0,64^{\mathrm{NS}}$ & $0,68^{\mathrm{NS}}$ & $1,49^{N S}$ & $1,58^{\mathrm{NS}}$ \\
\hline C.V. (\%) parcela & 6,35 & 21,73 & 13,04 & 22,99 \\
\hline C.V. (\%) subparcela & 5,71 & 8,71 & 8,17 & 18,43 \\
\hline
\end{tabular}

Médias seguidas de mesma letra na coluna não diferem entre si pelo teste de Tukey a $5 \%$ de probabilidade. C.V. = coeficiente de variação. NS = não signficativo. 
PELÁ, A. et al. Plantas de cobertura e adubação...

O número de grãos por espiga apresentou ajuste linear no intervalo entre as doses de $140 \mathrm{e}$ $700 \mathrm{~kg} \mathrm{ha}^{-1}$ de NPK (Figura 2b). Lucena et al. (2000) não verificaram diferenças no número de grãos por espiga em função de doses de N. Embora maiores valores absolutos tenham sido observados nos tratamentos com leguminosas, não houve diferenças significativas entre as coberturas do solo.

Verificou-se que a produtividade de grãos foi maior sobre a cobertura do solo proporcionada pelas crotalárias do que pela braquiária. Enquanto a última proporcionou produtividade média de 3989 $\mathrm{kg} \mathrm{ha}^{-1}$, com C. juncea e C. spectabilis obteve-se 5933 e $5600 \mathrm{~kg} \mathrm{ha}^{-1}$, respectivamente, provavelmente pelo efeito benéfico proporcionado pela rotação leguminosa/gramínea. Esses resultados corroboram com os obtidos por Collier et al. (2006) e Silva et al. (2006), que verificaram maior produtividade de grãos de milho sob resíduos de crotalária. Houve aumento linear na produtividade com a elevação das doses de NPK, passando de 4007 para $6207 \mathrm{~kg} \mathrm{ha}^{-1}$ de grãos, da dose de 140 para a de $700 \mathrm{~kg} \mathrm{ha}^{-1}$ de NPK (Figura 2c). Mesmo com o uso de doses de adubos NPK bem maiores que as normalmente usadas pelos produtores, até duas vezes e meia a quantidade recomendada com base na análise do solo, não foi possível atingir o máximo potencial produtivo da planta. Isso provavelmente ocorreu pelo fato da semeadura ter sido tardia em relação à época recomendada para a região, de setembro a novembro para safra normal, e final de fevereiro para safrinha (Sans \& Guimarães, 2007). O atraso na semeadura foi necessário para que as plantas de cobertura atingissem 0 desenvolvimento esperado. Resultados diferentes foram obtidos por Silva et al. (2006), que observaram respostas quadráticas na produtividade do milho com a aplicação de $\mathrm{N}$ (doses de 133 a $173 \mathrm{~kg} \mathrm{ha}^{-1}$ ), e que menores doses foram necessárias para crotalária em relação a pousio e milheto. Lucena et al. (2000) obtiveram máxima produtividade com aplicações de 111,1 e $197,6 \mathrm{~kg} \mathrm{ha}^{-1}$ de $\mathrm{N}$ e $\mathrm{P}_{2} \mathrm{O}_{5}$, respectivamente. Collier et al. (2006) obtiveram produtividade máxima com a dose de $100 \mathrm{~kg} \mathrm{ha}^{-1}$ de $\mathrm{N}$, com milho cultivado sobre resíduos de crotalária, enquanto que com feijão de porco o ajuste foi linear, à exemplo dos resultados obtidos por Gurgel \& Silva (2001), por Bastos et al. (2008) e neste experimento. Isso provavelmente ocorreu porque as doses dos três nutrientes exigidos em maiores quantidades pelas plantas foram aumentadas na mesma proporção, favorecendo-se o equilíbrio entre estes.

Os valores obtidos neste experimento estão acima da produtividade média nacional, que é de $3000 \mathrm{~kg} \mathrm{ha}^{-1}$, nas últimas safras e, com as doses mais elevadas, chegou a superar a média de Goiás, $5000 \mathrm{~kg} \mathrm{ha}^{-1}$ (CONAB, 2009), mesmo com a semeadura tardia, que prejudicou a produtividade. De acordo com Prado \& Fernandes (2001), a adubação é, reconhecidamente, o fator que mais afeta a produtividade e a sustentabilidade da atividade.

\section{CONCLUSÕES}

Os efeitos de doses de adubos NPK e de espécies usadas como plantas de cobertura sobre o desenvolvimento e produtividade da cultura foram independentes.

Usadas como plantas de cobertura, C. juncea e C. spectabilis proporcionaram melhor desenvolvimento e produtividade da cultura do milho que a braquiária.

$\mathrm{O}$ incremento das doses de adubos NPK promoveu melhor desenvolvimento e aumento na produtividade de grãos do milho.

\section{REFERÊNCIAS}

1. ALVARENGA, R.C. et al. Plantas de cobertura de solo para sistema plantio direto. Informe Agropecuário, v. 22, n. 208, p. 25-36, 2001.

2. ALVES, V. M. C. et al. Milho. In: RIBEIRO, A. C.; GUIMARÃES, P. T. G.; ALVAREZ V., V. H. (Ed.). Recomendação para o uso de corretivos e fertilizantes em Minas Gerais. 5. Aprox. Viçosa: Comissão de Fertilidade do Solo do Estado de Minas Gerais, 1999. p. 314-315.

3. ANDREOTTI, M. et al. Crescimento do milho em função da saturação por bases e da adubação potássica. Scientia Agricola, v. 58, n. 1, p. 145-150, 2001.

4. ARGENTA, G. et al. Resposta de híbridos simples de milho à redução do espaçamento entre linhas. Pesquisa Agropecuária Brasileira, v. 36, n. 1, p. 71-78, 2001.

5. BASTOS, E. A. et al. Doses e formas de parcelamento de nitrogênio para a produção de milho sob plantio direto. Revista Ciência Agronômica, v. 39, n. 2, p. 275-280, 2008.

6. CARVALHO, I.Q. et al. Espécies de cobertura de inverno e nitrogênio na cultura do milho em sistema de plantio direto. Scientia Agraria, v. 8, n. 2, p. 179-184, 2007.

7. COELHO, A. M.; FRANÇA, G. E. de. Seja o doutor do seu milho: nutrição e adubação. 2. ed. Piracicaba: Potafos 1995. 9 p.

8. COLLIER, L. S. et al. Manejo da adubação nitrogenada para o milho sob palhada de leguminosas em plantio direto em Gurupi, TO. Ciência Rural, v. 36, n. 4, p. 1100-1105, 2006.

9. CONAB - Companhia Nacional de Abastecimento. Milho total (1 ${ }^{\text {a }} \mathbf{2}^{\text {a }}$ safras) - Brasil. Disponível em: <http:/l www.conab.gov.br/conabweb/download/safra/MilhoTotalSerieHist.xls>. Acesso em: 27/07/2009.

10. CORREA, J. et al. Efeito do intervalo de dessecação antecedendo a semeadura do milho e uso de diferentes espécies de plantas de cobertura. Revista Brasileira de Ciência do Solo, v. 32, n. 2, p. 739-746, 2008.

11. DERPSCH, R.; SIDIRAS, N.; HEINZMANN, F.X. Manejo do solo com coberturas verdes de inverno. Pesquisa Agropecuária Brasileira, v. 20, n. 7, p. 761-773, 1985.

12. EMBRAPA. Empresa Brasileira de Pesquisa Agropecuária. Manual de métodos de análise de solo. 2 ed. rev. atual Rio de Janeiro: Centro Nacional de Pesquisa de Solos, 1997. 212 p. 
PELÁ, A. et al. Plantas de cobertura e adubação...

13. EMBRAPA. Empresa Brasileira de Pesquisa Agropecuária. Sistema brasileiro de classificação de solos. Rio de Janeiro: Centro Nacional de Pesquisa de Solos, 1999. 421 p.

14. FARIA, C. M. B.; COSTA, N. D.; FARIA, A. F. Atributos químicos de um argissolo e rendimento de melão mediante o uso de adubos verdes, calagem e adubação. Revista Brasileira de Ciência do Solo, v. 31, n. 2. p. 299-307, 2007.

15. FLEX, R.D.; VIEIRA, L.C. Espaçamentos e densidades de milho com diferentes ciclos no Oeste de Santa Catarina, Brasil. Ciência Rural, v. 34, n. 1, p. 25-31, 2004.

16. GURGEL, F. L.; SILVA, P. S. L. Efeitos do nitrogênio e da sua aplicação parcelada sobre os rendimentos de espigas verdes e de grãos de milho. Revista Ciência Agronômica, v. 32, n. 1, p. 30-37, 2001.

17. LUCENA, L. F. C. et al. Resposta do milho a diferentes dosagens de nitrogênio e fósforo. Revista Brasileira de Engenharia Agrícola e Ambiental, v. 4, n. 3, p. 334-337, 2000.

18. MOURA, J.B. et al. Produção de biomassa de plantas de cobertura no sudoeste goiano. In: CONGRESSO BRASILEIRO DE FERTILIDADE DO SOLO E NUTRIÇÃO DE PLANTAS, 27., 2006. Bonito. Anais... Bonito: Sociedade Brasileira de Ciência do Solo, 2006. 4p. (CD-ROM).

19. PELÁ, A. et al. Aspectos econômicos da adubação na produtividade de milho cultivado em espaçamento reduzido, sob diferentes densidades de plantas e doses de adubos. Trilhos, v. 6, n.1, p. 177-184, 2008.

20. PRADO, R.M.; FERNANDES, F.M. Aspectos econômicos da adubação fosfatada para a cultura do milho. Scientia Agrícola, v. 58, n. 3, p. 617-621, 2001.

21. SANS, L. M. A.; GUIMARÃES, D. P. Zoneamento agrícola. In.: CRUZ, J. C. (Ed.). Cultivo do milho. 3. ed. Sete Lagoas: Embrapa Milho e Sorgo, 2007. (Sistemas de Produção, 02). Disponível em: <http://www.cnpms.embrapa.br/ publicacoes/milho/zoneamento.htm>. Acesso em 31/07/2008.

22. SILVA, D.A. et al. Culturas antecessoras e adubação nitrogenada na cultura do milho, em sistema plantio direto. Revista Brasileira de Milho e Sorgo, v. 5, n. 1, p. 75-88, 2006.

23. SODRÉ FILHO, J. et al. Fitomassa e cobertura do solo de culturas de sucessão ao milho na Região do Cerrado. Pesquisa Agropecuária Brasileira, v. 39, n. 4, p. 327-334, 2004.

24. STRIEDER, M. L. et al. Crop management systems and maize grain yield under narrow row spacing. Scientia Agricola, v. 65, n. 4, p. 346-353, 2008.

25. TORRES, J. L. R.; PEREIRA, M. G.; FABIAN, A. J. Produção de fitomassa por plantas de cobertura e mineralização de seus resíduos em plantio direto. Pesquisa Agropecuária Brasileira, v. 43, n. 3, p. 421-428, 2008.

Recebido em 01/09/2009 Aceito em 13/10/2010 
